\title{
Overexpression of Myole promotes albumin endocytosis by mouse glomerular podocytes mediated by Dynamin
}

\author{
Huijun Shen ${ }^{\text {Corresp., }}{ }^{,}$, Yu Bao ${ }^{1}$, Chunyue Feng ${ }^{1}$, Haidong Fu ${ }^{1}$, Jianhua Mao ${ }^{1}$ \\ ${ }^{1}$ Department of Nephrology, The Children's Hospital of Zhejiang University School of Medicine, Hangzhou, Zhejiang, China \\ Corresponding Author: Huijun Shen \\ Email address: 6197005@zju.edu.cn
}

Background: As a fundamental process internalizing molecules from the plasma membrane, endocytosis plays a crucial role in podocyte biology. Our previous study has identified that overexpression of Myole may enhance podocyte endocytosis. However, its potential mechanism has been not well understand. Thus, we aimed to analyze whether albumin endocytosis by mouse glomerular podocytes is dependent on Myole expression. Also, we aimed to elucidate whether the underlying mechanism is mediated by Dynamin .

Methods: Firstly, mouse podocyte cells ( MPC5 ) were treated with different concentrations of FITCbovine serum albumin (BSA). The fluorescence intensity and cell viability were detected by flow cytometry and MTT assays, respectively. Afterwards, the optimal concentration of FITC-BSA was determined. Secondly, MPC5 cells were treated with Myole overexpression or knockdown. Cell morphology was observed under microscope. Immunofluorescence assay was used to determine the expression of F-actin. The protein expression of nephrin and podocin was detected by western blot. Flow cytometry was used to detect MPC5 cell apoptosis with annexin V. Finally, MPC5 cells were treated with Myole overexpression and/or Dynasore (a GTPase inhibitor of Dynamin). The fluorescence intensity was detected using flow cytometry assay.

Results: MPC5 endocytosis BSA was elevated with a concentration-dependent manner. MTT results showed that MPC5 cell viability was inhibited with a concentration-dependent manner. Myole overexpression promoted podocyte endocytic FITC-BSA, which was contrary to its knockdown. Under microscope, after inhibition of Myole, podocyte foot process fusion was observed. Myole overexpression promoted the expression of cytoskeleton F-actin and podocyte-specific molecules (nephrin and podocin) in podocyte endocytic FITC-BSA. Furthermore, we found that Myole promoted the apoptosis of podocytes. Dynasore attenuated the increase in endocytosis of FITC-BSA induced by Myole overexpression, suggesting that podocytes might mediate albumin endocytosis via Myole-DynaminAlbumin.

Conclusion: Our findings revealed that overexpression of Myole promotes albumin endocytosis in mouse glomerular podocyte endocytic albumin mediated by Dynamin. 
1 Overexpression of Myo1e promotes albumin endocytosis by mouse glomerular

\title{
2 podocytes mediated by Dynamin
}

3 Authors:

4 Huijun Shen ${ }^{1, *}: 6197005 @ z j u . e d u . c n$

5 Yu Bao': hybaoyu@163.com

6 Chunyue Feng ${ }^{1}$ : springmoonfeng@163.com

7 Haidong Fu': fhdhz@163.com

8 Jianhua Mao': maojh88@126.com

9 1. Department of Nephrology, The Children's Hospital of Zhejiang University School of

10 Medicine, No.57 Zhugan Lane, Xiacheng District, Hangzhou 310006, Zhejiang, P R China.

11 * Corresponding author: Huijun Shen

12 E-mail: 6197005@zju.edu.cn

13

Department of Nephrology, The Children's Hospital of Zhejiang University School of Medicine, No.57 Zhugan Lane, Xiacheng District, Hangzhou 310006, Zhejiang, P R China.

\begin{abstract}
:
Background: As a fundamental process internalizing molecules from the plasma membrane, endocytosis plays a crucial role in podocyte biology. Our previous study has identified that overexpression of Myole may enhance podocyte endocytosis. However, its potential mechanism has been not well understand. Thus, we aimed to analyze whether albumin endocytosis by mouse glomerular podocytes is dependent on Myole expression. Also, we aimed to elucidate whether the underlying mechanism is mediated by Dynamin.

Methods: Firstly, mouse podocyte cells (MPC5) were treated with different concentrations of FITC-bovine serum albumin (BSA). The fluorescence intensity and cell viability were detected by flow cytometry and MTT assays, respectively. Afterwards, the optimal concentration of FITC-BSA was determined. Secondly, MPC5 cells were treated with Myole overexpression or knockdown. Cell morphology was observed under microscope. Immunofluorescence assay was used to determine the expression of F-actin. The protein expression of nephrin and podocin was detected by western blot. Flow cytometry was used to detect MPC5 cell apoptosis with annexin V. Finally, MPC5 cells were treated with Myole overexpression and/or Dynasore (a GTPase inhibitor of Dynamin). The fluorescence intensity was detected using flow cytometry assay. Results: MPC5 endocytosis BSA was elevated with a concentration-dependent manner. MTT results showed that MPC5 cell viability was inhibited with a concentration-dependent manner. Myole overexpression promoted podocyte endocytic FITC-BSA, which was contrary to its knockdown. Under microscope, after inhibition of Myole, podocyte foot process fusion was observed. Myole overexpression promoted the expression of cytoskeleton F-actin and podocytespecific molecules (nephrin and podocin) in podocyte endocytic FITC-BSA. Furthermore, we
\end{abstract}


found that Myole promoted the apoptosis of podocytes. Dynasore attenuated the increase in endocytosis of FITC-BSA induced by Myole overexpression, suggesting that podocytes might mediate albumin endocytosis via Myole-Dynamin-Albumin.

Conclusion: Our findings revealed that overexpression of Myo1e promotes albumin endocytosis in mouse glomerular podocyte endocytic albumin mediated by Dynamin.

Key words: endocytosis; podocytes; MPC5; albumin; glomerular albuminuria

\section{Introduction:}

Albuminuria is a hallmark of nephropathy, usually caused by a deterioration in the integrity of the glomerular filtration barrier (Schiessl et al. 2016). The glomerular filtration barrier consists of a porous endothelium, basement membrane and podocytes. Podocytes are highly specialized and terminally differentiated visceral epithelial cells (Han et al. 2019). As an important component of the glomerular basement membrane, podocytes play an important role in maintaining the integrity of the glomerular filtration barrier (Brosius \& Coward 2014). Hartleben et al. reported that endoplasmic reticulum stress, excessive ubiquitination, proteinuria and glomerular lesions were observed in aging mice after podocyte-specific knockdown of autophagy-related 5 (Atg5) (Hartleben et al. 2010). Furthermore, down-regulation of Cullin-5 expression in UPS as a cytoskeletal protein of E3 ligase in UPS can cause edema, proteinuria and glomerular structural abnormalities in zebrafish, and endoplasmic reticulum stress in podocytes (Mao et al. 2013). These finding reveal that it is necessary to explore the mechanisms of abnormally expressed genes in the podocyte cells in the development of albuminuria (Tryggvason et al. 2006).

Myosins constitute a large multigene family of actin-based molecular motors in eukaryotes (Guhathakurta et al. 2018; Heissler \& Sellers 2016). According to the amino acid sequence of ATP hydrolysis region, myosins can be divided into 24 categories. Among them, Class I myosin consists of Myo1a Myo1h (Dumont et al. 2002). Myo1e contains a proline-rich TH2 and a Srchomology 3 (SH3) domain in addition to the TH1 domain (Cheng et al. 2012). Recent studies have shown that Myole is involved in the development of proteinuria. In 2009, Krendel et al. reported that Myole is expressed in glomerular epithelial cells of mice (Krendel et al. 2009). In mice with Myole knockdown, disappearance of podocytes and thickening of the basement membrane are found, eventually leading to proteinuria (Chase et al. 2012). Moreover, mutated Myole is detected in patients with proteinuria appear (Mele et al. 2011; Sanna-Cherchi et al. 2011). These studies indicate that Myole in podocytes could be involved in the development of proteinuria, which requires further exploration.

Endocytosis is a process of transporting extracellular substances into cells through the deformation movement of the plasma membrane (Doherty \& McMahon 2009). Studies have been found that albumin can directly induce podocyte and glomerular injury (Agrawal \& Smoyer 2017). As an example, Notch signaling activation promotes the effect of Dynamin-dependent podocyte endocytosis of nephrin, leading to proteinuria (Waters et al. 2012). Both in vitro and in 
vivo studies have found that, podocytes possess the function of endocytic albumin with time- and concentration-dependent manners (He et al. 2011). After albumin aggregation in podocytes, knockdown of CD2AP and activation of TRPC6 channels could induce endoplasmic reticulum stress via mediating $\mathrm{Ca}^{2+}$ influx, thereby promoting podocyte apoptosis (He et al. 2011). These studies demonstrate that the endocytic BSA in podocytes is associated with the formation of proteinuria, but the specific mechanisms are poorly understood. Based on above studies, we hypothesized that overexpression of Myole could promote albumin endocytosis by mouse glomerular podocytes mediated by Dynamin.

\section{Materials and methods:}

\section{Cell culture}

Murine kidney podocyte cell line MPC5 (Mount Sinai School of Medicine, New York, NY) were cultured in RPMI-1640 medium (SH30809.01B, Hyclone, China) plus 10\% fetal bovine serum (SH30084.03, Hyclone, China) and $10 \mathrm{U} / \mathrm{ml}$ mouse recombinant interferon- $\gamma$ at $33^{\circ} \mathrm{C}$ with $5 \% \mathrm{CO}_{2}$. To induce differentiation, MPC 3 cells were cultured for 14 days at $37^{\circ} \mathrm{C}$ without interferon- $\gamma$.

\section{Endocytosis}

MPC5 cells were seeded in 6-well plates $\left(2.5^{*} 10^{5} /\right.$ well $)$ in three duplicates. After $24 \mathrm{~h}$, the cells were treated with different concentrations $(0 \mathrm{ug} / \mathrm{ml}, 100 \mathrm{ug} / \mathrm{ml}, 250 \mathrm{ug} / \mathrm{ml}, 500 \mathrm{ug} / \mathrm{ml}$, $1 \mathrm{mg} / \mathrm{ml}$ ) of FITC-BSA (SF063, Solarbio, China) for $4 \mathrm{~h}$ in the dark. Flow cytometry was used to evaluate the endocytosis.

\section{MTT assay}

The MPC5 cells were seeded in $7 * 10^{3} / \mathrm{well}$. 200ul of FITC-BSA $(0 \mathrm{ug} / \mathrm{ml}, 100 \mathrm{ug} / \mathrm{ml}$, $250 \mathrm{ug} / \mathrm{ml}, 500 \mathrm{ug} / \mathrm{ml}, 1 \mathrm{mg} / \mathrm{ml}$ ) and RPMI-1640 medium suspension was added to each well, and cultured at $37^{\circ} \mathrm{C}$ for $4 \mathrm{~h}$. After medium change, the cells were cultured for another $24 \mathrm{~h}$. After that, the cells were treated with 20 ul MTT solution $(5 \mathrm{mg} / \mathrm{ml}$; M5655-1G, Sigma, USA) for $4 \mathrm{~h}$ at $37^{\circ} \mathrm{C} .150 \mathrm{ul}$ of DMSO was then added to each well for $10 \mathrm{~min}$. Absorbance was detected at $490 \mathrm{~nm}$.

\section{Plasmid transfection}

The Myole- or Dynamin- plasmid transfection was performed as our previous study (Jin et al. 2014). The shRNA targeting Myole (shMyole) and full length of Myole overexpression were synthesized in Invitrogen (Carlsbad, CA, USA). Furthermore, siRNAs targeting Dynamin (siDynamin) and full length of Dynamin overexpression were also synthesized. Then, the target sequences were cloned into pLenti6.3_MCS_IRES2-EGFP lentiviral vector. The lentiviral vectors with the target sequence of shMyole or siDynamin were transfected into HEK293FT cells. MPC5 cells were transfected with negative control shRNA (shNC), shMyole, empty pcDNA3.1 plasmid (empty vector), Myole-plasmid (Myole overexpression), negative control siRNA, siDynamin and Dynamin overexpression using Lipofectamine 2000 (Invitrogen), respectively. The cell morphology was observed under an optical microscope.

\section{Real-time quantitative PCR (RT-qPCR) analysis}


Total RNA was extracted from MPC5 cells using TaKaRa MiniBEST Universal RNA Extraction Kit (TaKaRa, Beijing, China). The cDNA was synthesized with M-MLV (Vazyme, Jiang Su, China). RT-qPCR was carried out using SYBR Green I Master (Roche, Beijing, China). The primers were as follows: Mus Myo1e, 5'-ACAGTGCGCAACAACAACTC-3' (forwards), 5'-TGATGCCAAGGCTTTGCTTC-3' (reverse); Mus Dynamin, 5'TTTGCCAATGCTCAGCAGAG-3' (forwards), 5'-TGCTTGCTTGACATGAAGCC-3' (reverse); Mus GAPDH, 5'-TGATGCCAAGGCTTTGCTTC-3' (forwards), 5'GATGGCAACAATCTCCACTTTG-3' (reverse). GAPDH was used as an internal control. The results were calculated using the $2^{-\Delta \Delta \mathrm{CT}}$ method.

\section{Immunofluorescence assay}

The cells were seeded into a 24 -well plate $\left(1^{*} 10^{5} /\right.$ well $)$ at $37^{\circ} \mathrm{C}$. After $24 \mathrm{~h}$ of transfection with empty vector, Myole-plasmid, shNC and shMyole, the medium was removed from the 24well plate. After washing twice in PBS, the expression of F-actin was stained by phalloidin and detected in MPC5 cells under a fluorescence microscopy (Olympus).

\section{Western blot analysis}

The MPC 5 cells transfected with empty vector, Myole-plasmid, shNC and shMyole were lysed with RIPA buffer on ice for 10-20 min, and centrifuged at $12,000 \mathrm{rpm}$ at $4^{\circ} \mathrm{C}$ for 3-5 min. Transfer the supernatant to a new $1.5 \mathrm{ml}$ EP tube. The protein in the supernatant was collected for western blot analysis. After separating on SDS-PAGE, the protein was transferred onto PVDF membrane. After that, the membrane was blocked using 5\% milk for $1 \mathrm{~h}$ at room temperature. The primary antibody was diluted with $1 \% \mathrm{BSA} / \mathrm{PBST}$, and the membrane was incubated overnight at $4{ }^{\circ} \mathrm{C}$ in a refrigerator. Afterwards, the PVDF membrane was incubated with a horseradish peroxidase-labeled secondary antibody diluted in 5\% milk/PBST for $1 \mathrm{~h}$ at room temperature. ECL was used to visualize the protein blots. The primary antibodies included goat anti-nephrin (1:100, Santa Cruz Biotechnology) and anti-podocin (1:100, Santa Cruz Biotechnology). The relative expression levels were corrected for GAPDH expression.

\section{Flow cytometry for apoptosis}

The MPC 3 cells were plated in 6-well plates $\left(2.5^{*} 10^{5}\right.$ cells $/$ well $)$ at $37^{\circ} \mathrm{C}$ and $5 \% \mathrm{CO}_{2}$. After 24h, Myole-plasmid and empty vector were transfected into MPC3 cells, respectively. After transfection for $24 \mathrm{~h}$, the cells was treated with Dynasore $(160 \mathrm{uM})$ for $24 \mathrm{~h}$. After that, the cells were washed twice with PBS, and then added $500 \mathrm{ul}$ of serum-free RPMI-1640 and different concentrations of $500 \mathrm{ug} / \mathrm{ml}$ FITC-BSA for $4 \mathrm{~h}$. Finally, the cells were collected for flow cytometry apoptosis assay. According to the manufactures' protocols, apoptotic MPC5 cells were stained with Annexin V-FITC/Propidium Iodide (PI) (Beckman Coulter Trading Co., Ltd., China, Shanghai), and then analyzed on CytoFLEX S Flow Cytometer (BD Biosciences).

\section{Statistical analysis}

Graphpad Prism 7.0 (San Diego, CA, USA) was used for statistical analyses. All experiments were independently repeated at least three times. The data were presented as mean \pm standard deviation (SD). Comparisons between two groups were analyzed with paired student's $t$ test. For pairwise multiple comparisons, one-way analysis of variance (ANOVA) was performed, followed by Tukey's multiple comparison test. P-value $<0.05$ was considered statistically 
159

160

161

162

163

164

165

166

167

168

169

170

171

172

173

174

175

176

177

178

179

180

181

182

183

197

198

significant.

\section{Results:}

\section{The optimal concentration of BSA when treating MPC5 cells}

We first determined the optimal concentration of endocytic BSA in podocytes. Flow cytometry was used to detect changes in fluorescence intensity after treatment with different concentrations of FITC-BSA for MPC-5 podocytes. The results showed that the higher the concentration of BSA, the higher the content of BSA phagocytized by MPC-5. When the concentration of BSA was $100 \mathrm{ug} / \mathrm{ml}$, the phagocytosis content of MPC5 was the lowest; when the concentration of BSA was $1 \mathrm{mg} / \mathrm{ml}(\mathrm{p}<0.001)$, the phagocytosis content of MPC 5 was the highest (Figure 1A, B). Next, we examined the effect of BSA on the proliferation of MPC-5 podocytes. The proliferation of cells was detected by MTT assay after treatment with different concentrations of BSA for MPC-5. The results showed that BSA-FITC $(250 \mathrm{ug} / \mathrm{ml}, 500 \mathrm{ug} / \mathrm{ml}$ and $1 \mathrm{mg} / \mathrm{ml})$ significantly inhibited MPC5 cell apoptosis ( $<<0.001$; Figure 1C).

Immunofluorescence results showed that the content of BSA phagocytized by MPC-5 was increasing depending on the concentration of BSA, which was consistent with flow cytometry results (Figure 1D). Combined with above results, $500 \mathrm{ug} / \mathrm{ml}$ BSA was selected for subsequent experiments.

Figure 1. Identification of the optimal concentration of BSA when treating MPC5 cells. (A, B) Flow cytometry assay results showing the endocytosis effects of MPC5 cells treated with different concentrations $(0 \mathrm{ug} / \mathrm{ml}, 100 \mathrm{ug} / \mathrm{ml}, 250 \mathrm{ug} / \mathrm{ml}, 500 \mathrm{ug} / \mathrm{ml}, 1 \mathrm{mg} / \mathrm{ml})$ of FITC-BSA. (C) The cell viability of MPC5 cells treated with different concentrations $(0 \mathrm{ug} / \mathrm{ml}, 100 \mathrm{ug} / \mathrm{ml}$, $250 \mathrm{ug} / \mathrm{ml}, 500 \mathrm{ug} / \mathrm{ml}, 1 \mathrm{mg} / \mathrm{ml}$ ) of FITC-BSA was evaluated using MTT assay. (D) Immunofluorescence showing the endocytosis effects of MPC5 cells treated with different concentrations of FITC-BSA. Scale bar, $50 \mu \mathrm{m}$. Compared to blank, $* * * p<0.001$.

\section{Overexpression of Myo1e enhances MPC5 glomerular podocyte endocytosis BSA}

We further observed the effects of Myole on endocytosis BSA. RT-qPCR results showed that Myo1e was successfully overexpressed (Figure 2A; $<<0.001$ ) and inhibited (Figure 2B; $\mathrm{p}<0.01)$. Flow cytometry results showed that MPC5 endocytosis BSA increased significantly after overexpression of Myole compared to empty vector group $(\mathrm{p}<0.001)$, however, MPC5 endocytosis BSA was significantly decreased after Myole knockdown compared to shNC group $(\mathrm{p}<0.01$; Figure 3A, B), which was consistent with immunofluorescence results (Figure 3C). The above results indicated that Myole may promote MPC5 endocytic BSA. In addition, we observed the effect of abnormally expressed Myole on the morphology of MPC5 cells. As shown in Figure 4, compared with empty vector group, when Myole was overexpressed, we observed that the MPC5 cell morphology was irregular, the somas became larger, the foot processes were thinner and longer, and some of the podocytes also had a dendritic bifurcation. After the knockdown of Myole, the somas were shrunk, the edges were not neat, and the cells were fused.

Figure 2. The effects of Myo1e overexpression or knockdown. RT-qPCR results showed that 
199

200

201

202

203

204

205

206

207

208

209

210

211

212

213

214

215

216

217

218

219

220

221

222

223

224

225

226

227

228

229

230

231

232

233

234

235

236

237

238

239

Myole was successfully overexpressed (A) or inhibited (B). ${ }^{* *} \mathrm{p}<0.01 ; * * * \mathrm{p}<0.0001$.

Figure 3. Overexpression of Myo1e enhances MPC5 glomerular podocyte endocytosis BSA. (A, B) Flow cytometry assay results showing the endocytosis effects of MPC5 cells. (C) Immunofluorescence results showing the endocytosis effects of MPC5 cells. Scale bar, $50 \mu \mathrm{m}$.

$* * *$ Myole overexpression vs. empty vector, $\mathrm{p}<0.001$; \#\#shMyo1e vs. $\operatorname{shNC}, \mathrm{p}<0.01$.

Figure 4. Morphology changes of MPC5 cells when overexpression or knockdown of Myo1e $(100 \times, 200 \times)$.

Myo1e may promote the expression of F-actin in MPC5 cells

We further analyzed the effect of Myole overexpression/knockout on F-actin expression in MPC5 cells. The immunofluorescence results showed that the fluorescence intensity of F-actin increased after overexpression of Myole gene compared with empty vector group (Figure 5). However, the fluorescence intensity of F-actin decreased when Myole expression was inhibited compared to shNC group. The experimental results suggested that Myole may promote the expression of F-actin in MPC5 cells.

Figure 5. Immunofluorescence detection of $\mathrm{F}$-actin expression in MPC5 cells treated with Myo1e overexpression or knockdown. Scale bar, $50 \mu \mathrm{m}$.

Myo1e may promote the expression of nephrin and podocin in MPC5 cells

The western blot analysis results showed that the expression of nephrin and podocin increased after Myole overexpression compared with empty vector group (Figure 6A-C). However, the expression of nephrin and podocin decreased when knockdown Myole compared to shNC group (Figure 6A-C). Our results indicated that the Myole may promote the expression of nephrin and podocin in MPC5 cells.

Figure 6. Western blot analyses showing the expression levels of nephrin and podocin in MPC5 cells treated with Myo1e overexpression/knockdown. (A) Representative images of protein blots. (B) The expression levels of nephrin. (C) The expression levels of podocin. ** $\mathrm{p}<0.01 ; * * * \mathrm{p}<0.001$.

\section{Myo1e may promote MPC5 cell apoptosis}

The flow cytometry results showed that compared with the empty vector group, after overexpression of Myole, the apoptosis of MPC5 cells significantly increased $(\mathrm{p}<0.05$; Figure 7A, B). However, the apoptosis of MPC5 cells significantly decreased when Myo1e knockdown compared to shNC group $(\mathrm{p}<0.001$; Figure 7A, B). The experimental results indicated that Myole may promote apoptosis of MPC5 cells.

Figure 7. Myo1e may promote MPC5 cell apoptosis. (A, B) Flow cytometry showing the apoptosis of MPC5 cells when treated with Myo1e overexpression/knockdown. * Myole overexpression vs. empty vector, $\mathrm{p}<0.05$; \#\#\# shMyo1e vs. $\mathrm{shNC}, \mathrm{p}<0.001$. Myo1e might promote MPC5 endocytosis BSA mediated by Dynamin

We further explored how Myole enhanced glomerular podocyte endocytosis of BSA. From the experimental results, it was found that MPC5 endocytosis BSA was significantly reduced after MPC5 cells treated with a GTPase inhibitor of Dynamin, Dynasore (Figure 8A, B). In addition, compared with the MPC5 + Myole overexpression group, MPC5 endocytosis BSA was significantly inhibited after MPC5 cells treated with Dynasore (Figure 8A, B). The effect of 
240 Dynosore on both Myole and Dynamin expression was examined using RT-qPCR. The results 241 showed that Dynosore significantly inhibited the expression of Dynamin (Figure 8C), however, 242 it did not affect the expression of Myo1e (Figure 8D). Above results indicated that Dynasore can 243 inhibit MPC5 endocytosis BSA.

244 As shown in Figure 9A, RT-qPCR results showed that Dynamin was successfully 245 overexpressed $(\mathrm{p}<0.001)$. Furthermore, three siRNAs targeting Dynamin was synthesized. RT246 qPCR results showed that MPC5 cells treated with Dynamin-siRNA2 had the lowest expression 247 levels of Dynamin $(\mathrm{p}<0.001$; Figure 9B). Thus, Dynamin-siRNA2 was used for further 248 experiments. Immunofluorescence results showed that Dynamin knockdown inhibited MPC5 endocytosis BSA, while its overexpression promoted MPC5 endocytosis BSA (Figure 10). Furthermore, Dynamin knockdown decreased the effect of MPC5 endocytosis BSA induced by Myole overexpression (Figure 10). We also found that Dynamin overexpression ameliorated the inhibitory effect of MPC5 endocytosis BSA induced by Myo1e knockdown (Figure 10). These results indicated that podocytes mediate albumin endocytosis through Myole-Dynamin-albumin. Figure 8. Myo1e might promote MPC5 endocytosis BSA mediated by Dynamin. (A, B) Flow cytometry showing the endocytosis effects of MPC5 cells. (C, D) RT-qPCR showing the effect of Dynosore on both Myo1e and Dynamin expression. * $\mathrm{p}<0.05 ; * * \mathrm{p}<0.01 ; * * * \mathrm{p}<0.001$. that Dynamin was successfully overexpressed (A) or silenced (B). ***p $<0.0001$. mediated by Dynamin. Scale bar, $50 \mu \mathrm{m}$.

261

\section{Discussion:}

Proteinuria, mainly characterized by albuminuria, is not only a marker but also a known risk factor for progressive glomerular disease. Tubulointerstitial damage has been a field of widespread interest in this animal model. In addition, in vitro studies have revealed the role of serum albumin and its binding factors as mediators of proximal tubule cell damage, however, its molecular role in podocytes is not well understood. The response of podocytes to serum albumin includes albumin endocytosis and apoptosis. Myole plays an important role in renal function. Previous research has reported that the podocyte-specific knockout myole was performed using Cre-mediated recombination controlled by the podocin promoter (Chase et al. 2012). Loss of Myole in podocytes results in proteinuria, disappearance of the podocyte process and disintegration of the glomerular basement membrane. Podocytes can endocytose proteins, including albumin, immunoglobulins and transferrin, in a receptor-mediated manner. In our previous studies, we analyzed endocytic FITC-transferrin by podocyte analysis by quantitative analysis and fluorescence microscopy. After co-culture of podocytes with FITC-transferrin, the number of cells with FITC-positive vesicles in somatic cells treated with Myole knockdown was significantly decreased. However, FITC-transferrin was observed in abundant large vesicles in podocytes, especially in podocytes overexpressing Myole. Our previous study indicated that inhibition of Myole expression may reduce the efficiency of endocytic FITC-transferrin in 
280

281

282

283

284

285

286

287

288

289

290

291

292

293

294

295

296

297

298

299

300

301

302

303

304

305

306

307

308

309

310

311

312

313

314

315

316

317

318

319

320

podocytes. Our previous study has identified that Myole was expressed in the mouse podocytes of glomeruli, furthermore, overexpression of Myole may promote cellular endocytosis, migration, and adhesion (Jin et al. 2014). However, the specific mechanisms remain unclear. BSA is a main porotein component of proteinuria, therefore, in our current study, we observed the podocyte endocytosis of FITC-BSA by fluorescence microscopy in a concentrationdependent manner. The MTT assay showed that FITC-BSA inhibited podocyte proliferation in a concentration-dependent manner.

In this study, we found that overexpression/knockdown of Myole can cause changes in the function and morphology of endocytic albumin in podocytes. Our results showed that overexpression of Myole promoted the ability of podocytes to endocytosis and while knockdown of Myole inhibited the ability of podocytes to endocytosis. Renal biopsy in patients with proteinuria usually manifests as the disappearance of podocyte foot processes. We found that MPC5 cells treated with knockdown of Myole appeared foot process fusion, which was contrary to MPC5 cells treated with overexpression of Myole. Myole may ameliorate podocyte foot process fusion of patients with proteinuria (Perysinaki et al. 2011).

F-actin cytoskeletal disruption is a typical characteristic of podocyte injury. F-actin cytoskeleton has been shown to be critical for maintaining the specific morphology of podocyte foot processes (Allison 2015; Hu et al. 2017; Schiffer et al. 2015). Destruction of the F-actin cytoskeleton in podocytes results in the disappearance of the foot process and is associated with the pathogenesis of proteinuria ( $\mathrm{Ni}$ et al. 2018). In our study, immunofluorescence results showed that Myole overexpression promoted the expression of F-actin in MPC5 cells, which was contrary to its knockdown. Thus, Myole may play an important role in podocyte endocytosis by regulating the actin cytoskeleton F-actin.

Slit membrane proteins are essential molecular components of the glomerular filtration barrier and are also involved in actin polymerization (Kim et al. 2016). As podocyte-specific proteins, nephrin and podocin play important roles in the function of the glomerular filtration barrier (Ni et al. 2017). The disappearance of the foot process may be due to diaphragm rupture and podocyte damage. Nephrin is a structural component of a slit membrane formed by adjacent podocytes (Ruotsalainen et al. 1999). The absence of nephrin contributes to proteinuria and foot process effacement (Teng et al. 2016). Podocin is a key factor in maintaining the steady state of the slit diaphragm. Our results showed that overexpression of Myole promoted the expression of nephrin and podocin in MPC5 cells. However, the expression of nephrin and podocin decreased when knockdown of Myole in MPC5 cells. These results indicated that Myole may be involved in maintaining slit membrane by nephrin and podocin. Increasing evidence suggests that the expression of nephrin and podocin could be regulated by many factors. For example, microRNA29a may promote nephrin acetylation to improve hyperglycemia-induced podocyte dysfunction (Lin et al. 2014). Another research found that vitamin D3 ameliorates podocyte injury via targeting nephrin (Trohatou et al. 2017).

Podocyte injury has been shown to contribute to the development of proteinuria ( $\mathrm{Li}$ et al. 2019). Our findings showed that overexpression of Myole promoted apoptosis of MPC5 cells that were co-cultured with BSA, indicating that overexpression of Myole may induce podocyte 
321

322

323

324

325

326

327

328

329

330

331

332

333

334

335

336

337

338

339

340

341

342

343

344

345

346

347

348

349

350

351

352

353

354

355

356

357

358

injury. There are several pathways of albumin endocytosis, such as Dynamin-dependent podocyte endocytosis, FcRn-mediated albumin transcytosis (Kinugasa et al. 2011), clathrinmediated endocytosis (Soda et al. 2012), caveolin-mediated endocytosis (Dobrinskikh et al. 2014), fluid phase-endocytosis (Palm et al. 2015) and dynein-microtubule related vesicle transport (Tojo et al. 2017). Dynamin plays a crucial role in maintaining the structure and function of the glomerular filtration barrier. Dynamin regulates the actin cytoskeleton and the turnover of nephrin in podocytes, furthermore, knockdown of dynamin leads to proteinuria (Khalil et al. 2019). Dynamin-dependent podocyte endocytosis is one of the pathways of albumin endocytosis. In our study, we found that Dynasore attenuated the increase in endocytosis of albumin induced by Myole overexpression. As a GTPase inhibitor of Dynamin, these results indicated that podocytes might mediate albumin endocytosis by Myo1e-Dynamin-Albumin.

\section{Conclusion:}

In our study, our results showed that Myole promoted podocyte endocytic albumin, however, after inhibition of Myole, podocyte foot process fusion was observed. Furthermore, we found that Myole promoted apoptosis of podocytes. Myole elevated the expression of podocytespecific molecules (nephrin and podocin) and cytoskeleton F-actin in podocyte endocytic albumin. Dynasore attenuated the increase in endocytosis of albumin induced by Myole overexpression, suggesting that podocytes might mediate albumin endocytosis via MyoleDynamin-Albumin.

\section{Abbreviations:}

BSA: bovine serum albumin.

\section{Declarations:}

1. Acknowledgements

Not applicable.

\section{Funding}

This work was funded by The Zhejiang Provincial Natural Science Foundation of China (LH14H050002).

3. Ethics approval and consent to participate

Not applicable.

4. Consent for publication

Not applicable.

5. Conflicts of Interest

The authors declare no conflicts of interest.

\section{References:}


359

360

361

362

363

364

365

366

367

368

369

370

371

372

373

374

375

376

377

378

379

380

381

382

383

384

385

386

387

388

389

390

391

392

393

394

395

396

397

398

399

Agrawal S, and Smoyer WE. 2017. Role of albumin and its modifications in glomerular injury. Pflugers Arch 469:975-982. 10.1007/s00424-017-2029-4

Allison SJ. 2015. Chronic kidney disease: Actin cytoskeleton alterations in podocytes: a therapeutic target for chronic kidney disease. Nat Rev Nephrol 11:385. 10.1038/nrneph.2015.79

Brosius FC, and Coward RJ. 2014. Podocytes, signaling pathways, and vascular factors in diabetic kidney disease. Adv Chronic Kidney Dis 21:304-310. 10.1053/j.ackd.2014.03.011

Chase SE, Encina CV, Stolzenburg LR, Tatum AH, Holzman LB, and Krendel M. 2012. Podocyte-specific knockout of myosin 1e disrupts glomerular filtration. Am J Physiol Renal Physiol 303:F1099-1106. 10.1152/ajprenal.00251.2012

Cheng J, Grassart A, and Drubin DG. 2012. Myosin 1E coordinates actin assembly and cargo trafficking during clathrin-mediated endocytosis. Mol Biol Cell 23:2891-2904. 10.1091/mbc.E11-04-0383

Dobrinskikh E, Okamura K, Kopp JB, Doctor RB, and Blaine J. 2014. Human podocytes perform polarized, caveolae-dependent albumin endocytosis. Am J Physiol Renal Physiol 306:F941-951. 10.1152/ajprenal.00532.2013

Doherty GJ, and McMahon HT. 2009. Mechanisms of endocytosis. Annu Rev Biochem 78:857902. 10.1146/annurev.biochem.78.081307.110540

Dumont RA, Zhao YD, Holt JR, Bahler M, and Gillespie PG. 2002. Myosin-I isozymes in neonatal rodent auditory and vestibular epithelia. J Assoc Res Otolaryngol 3:375-389. $10.1007 / \mathrm{s} 101620020049$

Guhathakurta P, Prochniewicz E, and Thomas DD. 2018. Actin-Myosin Interaction: Structure, Function and Drug Discovery. Int J Mol Sci 19. 10.3390/ijms19092628

Han X, Li Q, Wang C, and Li Y. 2019. MicroRNA-204-3p Attenuates High Glucose-Induced MPC5 Podocytes Apoptosis by Targeting Braykinin B2 Receptor. Exp Clin Endocrinol Diabetes 127:387-395. 10.1055/a-0630-0173

Hartleben B, Godel M, Meyer-Schwesinger C, Liu S, Ulrich T, Kobler S, Wiech T, Grahammer F, Arnold SJ, Lindenmeyer MT, Cohen CD, Pavenstadt H, Kerjaschki D, Mizushima N, Shaw AS, Walz G, and Huber TB. 2010. Autophagy influences glomerular disease susceptibility and maintains podocyte homeostasis in aging mice. J Clin Invest 120:10841096. 10.1172/jci39492

He F, Chen S, Wang H, Shao N, Tian X, Jiang H, Liu J, Zhu Z, Meng X, and Zhang C. 2011. Regulation of CD2-associated protein influences podocyte endoplasmic reticulum stressmediated apoptosis induced by albumin overload. Gene 484:18-25. 10.1016/j.gene.2011.05.025

Heissler SM, and Sellers JR. 2016. Various Themes of Myosin Regulation. J Mol Biol 428:19271946. 10.1016/j.jmb.2016.01.022

Hu M, Fan M, Zhen J, Lin J, Wang Q, Lv Z, and Wang R. 2017. FAK contributes to proteinuria in hypercholesterolaemic rats and modulates podocyte $\mathrm{F}$-actin re-organization via activating p38 in response to ox-LDL. J Cell Mol Med 21:552-567. 10.1111/jcmm.13001 
400

401

402

403

404

405

406

407

408

409

410

411

412

413

414

415

416

417

418

419

420

421

422

423

424

425

426

427

428

429

430

431

432

433

434

435

436

437

438

439

440

Jin X, Wang W, Mao J, Shen H, Fu H, Wang X, Gu W, Liu A, Yu H, Shu Q, and Du L. 2014. Overexpression of Myole in mouse podocytes enhances cellular endocytosis, migration, and adhesion. $J$ Cell Biochem 115:410-419. 10.1002/jcb.24676

Khalil R, Koop K, Kreutz R, Spaink HP, Hogendoorn PC, Bruijn JA, and Baelde HJ. 2019. Increased dynamin expression precedes proteinuria in glomerular disease. $J$ Pathol 247:177-185. 10.1002/path.5181

Kim SH, Kim HJ, and Kim CW. 2016. GLCCI1 is a novel component associated with the PI3K signaling pathway in podocyte foot processes. Exp Mol Med 48:e233. 10.1038/emm.2016.28

Kinugasa S, Tojo A, Sakai T, Tsumura H, Takahashi M, Hirata Y, and Fujita T. 2011. Selective albuminuria via podocyte albumin transport in puromycin nephrotic rats is attenuated by an inhibitor of NADPH oxidase. Kidney Int 80:1328-1338. 10.1038/ki.2011.282

Krendel M, Kim SV, Willinger T, Wang T, Kashgarian M, Flavell RA, and Mooseker MS. 2009. Disruption of Myosin 1e promotes podocyte injury. J Am Soc Nephrol 20:86-94. 10.1681/asn.2007111172

Li X, Ma A, and Liu K. 2019. Geniposide alleviates lipopolysaccharide-caused apoptosis of murine kidney podocytes by activating Ras/Raf/MEK/ERK-mediated cell autophagy. Artif Cells Nanomed Biotechnol 47:1524-1532. 10.1080/21691401.2019.1601630

Lin CL, Lee PH, Hsu YC, Lei CC, Ko JY, Chuang PC, Huang YT, Wang SY, Wu SL, Chen YS, Chiang WC, Reiser J, and Wang FS. 2014. MicroRNA-29a promotion of nephrin acetylation ameliorates hyperglycemia-induced podocyte dysfunction. J Am Soc Nephrol 25:1698-1709. 10.1681/asn.2013050527

Mao J, Wang D, Mataleena P, He B, Niu D, Katayama K, Xu X, Ojala JR, Wang W, Shu Q, Du L, Liu A, Pikkarainen T, Patrakka J, and Tryggvason K. 2013. Myole impairment results in actin reorganization, podocyte dysfunction, and proteinuria in zebrafish and cultured podocytes. PLoS One 8:e72750. 10.1371/journal.pone.0072750

Mele C, Iatropoulos P, Donadelli R, Calabria A, Maranta R, Cassis P, Buelli S, Tomasoni S, Piras R, Krendel M, Bettoni S, Morigi M, Delledonne M, Pecoraro C, Abbate I, Capobianchi MR, Hildebrandt F, Otto E, Schaefer F, Macciardi F, Ozaltin F, Emre S, Ibsirlioglu T, Benigni A, Remuzzi G, and Noris M. 2011. MYO1E mutations and childhood familial focal segmental glomerulosclerosis. $N$ Engl J Med 365:295-306. 10.1056/NEJMoa1101273

Ni Y, Wang X, Yin X, Li Y, Liu X, Wang H, Liu X, Zhang J, Gao H, Shi B, and Zhao S. 2018. Plectin protects podocytes from adriamycin-induced apoptosis and F-actin cytoskeletal disruption through the integrin alpha6beta4/FAK/p38 MAPK pathway. J Cell Mol Med 22:5450-5467. 10.1111/jcmm.13816

Ni Z, Tao L, Xiaohui X, Zelin Z, Jiangang L, Zhao S, Weikang H, Hongchao X, Qiujing W, and Xin L. 2017. Polydatin impairs mitochondria fitness and ameliorates podocyte injury by suppressing Drp1 expression. J Cell Physiol 232:2776-2787. 10.1002/jcp.25943

Palm W, Park Y, Wright K, Pavlova NN, Tuveson DA, and Thompson CB. 2015. The Utilization of Extracellular Proteins as Nutrients Is Suppressed by mTORC1. Cell 
162:259-270. 10.1016/j.cell.2015.06.017

Perysinaki GS, Moysiadis DK, Bertsias G, Giannopoulou I, Kyriacou K, Nakopoulou L, Boumpas DT, and Daphnis E. 2011. Podocyte main slit diaphragm proteins, nephrin and podocin, are affected at early stages of lupus nephritis and correlate with disease histology. Lupus 20:781-791. 10.1177/0961203310397412

Ruotsalainen V, Ljungberg P, Wartiovaara J, Lenkkeri U, Kestila M, Jalanko H, Holmberg C, and Tryggvason K. 1999. Nephrin is specifically located at the slit diaphragm of glomerular podocytes. Proc Natl Acad Sci U S A 96:7962-7967. 10.1073/pnas.96.14.7962

Sanna-Cherchi S, Burgess KE, Nees SN, Caridi G, Weng PL, Dagnino M, Bodria M, Carrea A, Allegretta MA, Kim HR, Perry BJ, Gigante M, Clark LN, Kisselev S, Cusi D, Gesualdo L, Allegri L, Scolari F, D'Agati V, Shapiro LS, Pecoraro C, Palomero T, Ghiggeri GM, and Gharavi AG. 2011. Exome sequencing identified MYO1E and NEIL1 as candidate genes for human autosomal recessive steroid-resistant nephrotic syndrome. Kidney Int 80:389-396. 10.1038/ki.2011.148

Schiessl IM, Hammer A, Kattler V, Gess B, Theilig F, Witzgall R, and Castrop H. 2016. Intravital Imaging Reveals Angiotensin II-Induced Transcytosis of Albumin by Podocytes. J Am Soc Nephrol 27:731-744. 10.1681/asn.2014111125

Schiffer M, Teng B, Gu C, Shchedrina VA, Kasaikina M, Pham VA, Hanke N, Rong S, Gueler F, Schroder P, Tossidou I, Park JK, Staggs L, Haller H, Erschow S, Hilfiker-Kleiner D, Wei C, Chen C, Tardi N, Hakroush S, Selig MK, Vasilyev A, Merscher S, Reiser J, and Sever S. 2015. Pharmacological targeting of actin-dependent dynamin oligomerization ameliorates chronic kidney disease in diverse animal models. Nat Med 21:601-609. 10.1038/nm.3843

Soda K, Balkin DM, Ferguson SM, Paradise S, Milosevic I, Giovedi S, Volpicelli-Daley L, Tian X, Wu Y, Ma H, Son SH, Zheng R, Moeckel G, Cremona O, Holzman LB, De Camilli P, and Ishibe S. 2012. Role of dynamin, synaptojanin, and endophilin in podocyte foot processes. J Clin Invest 122:4401-4411. 10.1172/jci65289

Teng B, Schroder P, Muller-Deile J, Schenk H, Staggs L, Tossidou I, Dikic I, Haller H, and Schiffer M. 2016. CIN85 Deficiency Prevents Nephrin Endocytosis and Proteinuria in Diabetes. Diabetes 65:3667-3679. 10.2337/db16-0081

Tojo A, Hatakeyama S, Kinugasa S, Fukuda S, and Sakai T. 2017. Enhanced podocyte vesicle transport in the nephrotic rat. Med Mol Morphol 50:86-93. 10.1007/s00795-016-0151-6

Trohatou O, Tsilibary EF, Charonis A, Iatrou C, and Drossopoulou G. 2017. Vitamin D3 ameliorates podocyte injury through the nephrin signalling pathway. J Cell Mol Med 21:2599-2609. 10.1111/jcmm.13180

Tryggvason K, Patrakka J, and Wartiovaara J. 2006. Hereditary proteinuria syndromes and mechanisms of proteinuria. $N$ Engl J Med 354:1387-1401. 10.1056/NEJMra052131

Waters AM, Wu MY, Huang YW, Liu GY, Holmyard D, Onay T, Jones N, Egan SE, Robinson LA, and Piscione TD. 2012. Notch promotes dynamin-dependent endocytosis of nephrin. J Am Soc Nephrol 23:27-35. 10.1681/asn.2011010027 


\section{Figure legends:}

483 Figure 1. Identification of the optimal concentration of BSA when treating MPC5 cells. (A, B)

484

485

486

487

488

489

490

491

492

493

494

495

496

497

498

499

500

501

502

503

504

505

506

507

508

509

510

511

512

513
Flow cytometry assay results showing the endocytosis effects of MPC5 cells treated with different concentrations ( $0 \mathrm{ug} / \mathrm{ml}, 100 \mathrm{ug} / \mathrm{ml}, 250 \mathrm{ug} / \mathrm{ml}, 500 \mathrm{ug} / \mathrm{ml}, 1 \mathrm{mg} / \mathrm{ml}$ ) of FITC-BSA. (C) The cell viability of MPC5 cells treated with different concentrations $(0 \mathrm{ug} / \mathrm{ml}, 100 \mathrm{ug} / \mathrm{ml}$, $250 \mathrm{ug} / \mathrm{ml}, 500 \mathrm{ug} / \mathrm{ml}, 1 \mathrm{mg} / \mathrm{ml}$ ) of FITC-BSA was evaluated using MTT assay. (D) Immunofluorescence showing the endocytosis effects of MPC5 cells treated with different concentrations of FITC-BSA. Scale bar, $50 \mu \mathrm{m}$. Compared to blank, ${ }^{* * *} \mathrm{p}<0.001$.

Figure 2. The effects of Myole overexpression or knockdown. RT-qPCR results showed that Myole was successfully overexpressed (A) or inhibited (B). ${ }^{* *} p<0.01 ; * * * p<0.0001$.

Figure 3. Overexpression of Myole enhances MPC5 glomerular podocyte endocytosis BSA. (A, B) Flow cytometry assay results showing the endocytosis effects of MPC5 cells. (C) Immunofluorescence results showing the endocytosis effects of MPC5 cells. Scale bar, $50 \mu \mathrm{m}$. $* * *$ Myole overexpression vs. empty vector, $\mathrm{p}<0.001$; \#\#shMyole vs. $\mathrm{shNC}, \mathrm{p}<0.01$. Figure 4. Morphology changes of MPC5 cells when overexpression or knockdown of Myole $(100 \times, 200 \times)$.

Figure 5. Immunofluorescence detection of F-actin expression in MPC5 cells treated with Myole overexpression or knockdown. Scale bar, $50 \mu \mathrm{m}$.

Figure 6. Western blot analyses showing the expression levels of nephrin and podocin in MPC5 cells treated with Myole overexpression/knockdown. (A) Representative images of protein blots. (B) The expression levels of nephrin. (C) The expression levels of podocin. ** $\mathrm{p}<0.01$; *** $\mathrm{p}<0.001$.

Figure 7. Myole may promote MPC5 cell apoptosis. (A, B) Flow cytometry showing the apoptosis of MPC5 cells when treated with Myole overexpression/knockdown. * Myole overexpression vs. empty vector, $\mathrm{p}<0.05$; \#\#\# shMyo1e vs. $\operatorname{shNC}, \mathrm{p}<0.001$.

Figure 8. Myole might promote MPC5 endocytosis BSA mediated by Dynamin. (A, B) Flow cytometry showing the endocytosis effects of MPC5 cells. (C, D) RT-qPCR showing the effect of Dynosore on both Myo1e and Dynamin expression. * $\mathrm{p}<0.05 ; * * \mathrm{p}<0.01 ; * * * \mathrm{p}<0.001$.

Figure 9. The effects of Dynamin overexpression or knockdown. RT-qPCR results showed that Dynamin was successfully overexpressed (A) or silenced (B). $* * * p<0.0001$.

Figure 10. Immunofluorescence showing Myo1e might promote MPC5 endocytosis BSA mediated by Dynamin. Scale bar, $50 \mu \mathrm{m}$. 


\section{Figure 1}

Identification of the optimal concentration of BSA when treating MPC5 cells.

(A, B) Flow cytometry assay results showing the endocytosis effects of MPC5 cells treated with different concentrations ( $0 \mathrm{ug} / \mathrm{ml}, 100 \mathrm{ug} / \mathrm{ml}, 250 \mathrm{ug} / \mathrm{ml}, 500 \mathrm{ug} / \mathrm{ml}, 1 \mathrm{mg} / \mathrm{ml}$ ) of FITC-BSA.

(C) The cell viability of MPC5 cells treated with different concentrations $(0 \mathrm{ug} / \mathrm{ml}, 100 \mathrm{ug} / \mathrm{ml}$, $250 \mathrm{ug} / \mathrm{ml}, 500 \mathrm{ug} / \mathrm{ml}, 1 \mathrm{mg} / \mathrm{ml}$ ) of FITC-BSA was evaluated using MTT assay. (D) Immunofluorescence showing the endocytosis effects of MPC5 cells treated with different concentrations of FITC-BSA. Scale bar, $50 \mu \mathrm{m}$. Compared to blank, $* * * p<0.001$.

A
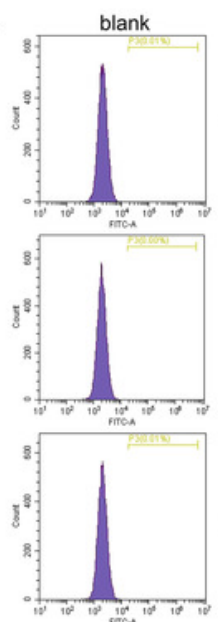

B
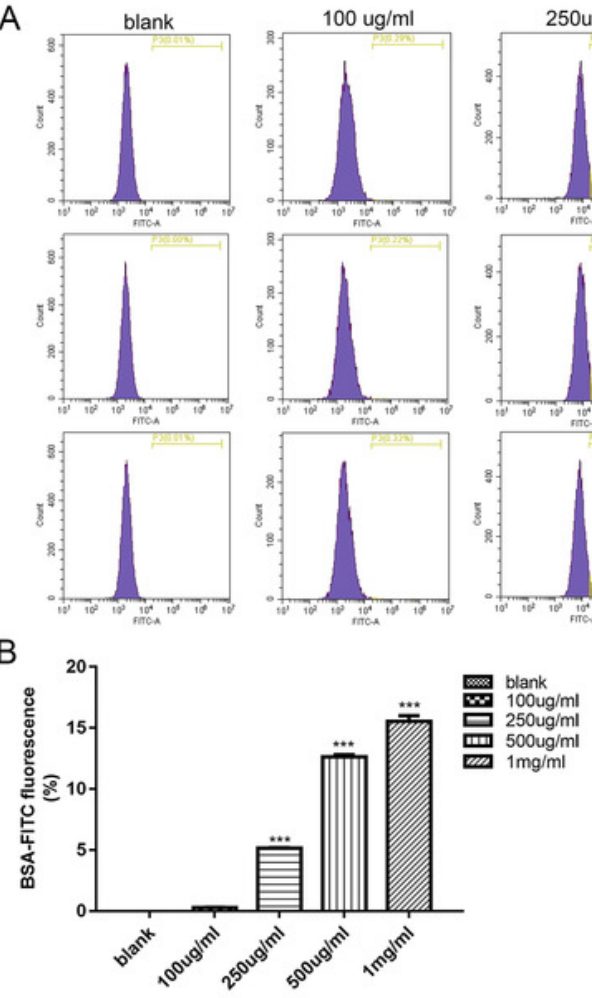

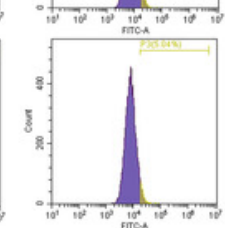

C
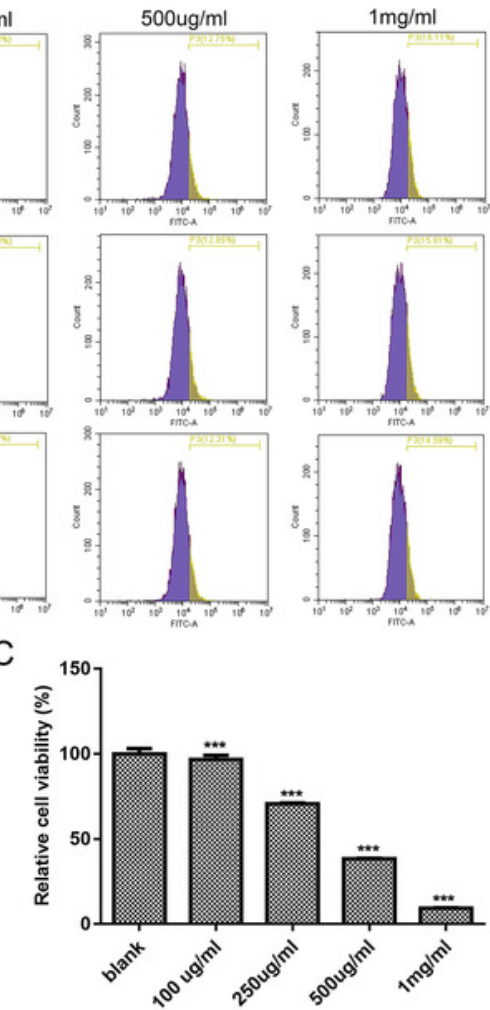

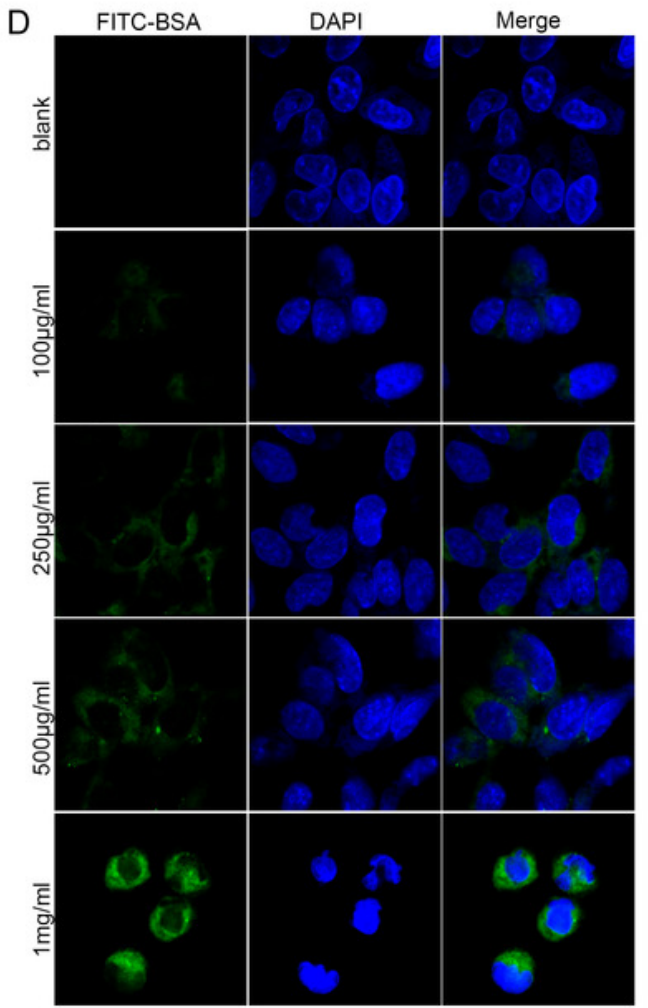


Figure 2

The effects of Myole overexpression or knockdown.

RT-qPCR results showed that Myole was successfully overexpressed (A) or inhibited (B). $* * p<0.01 ; * * * p<0.0001$.
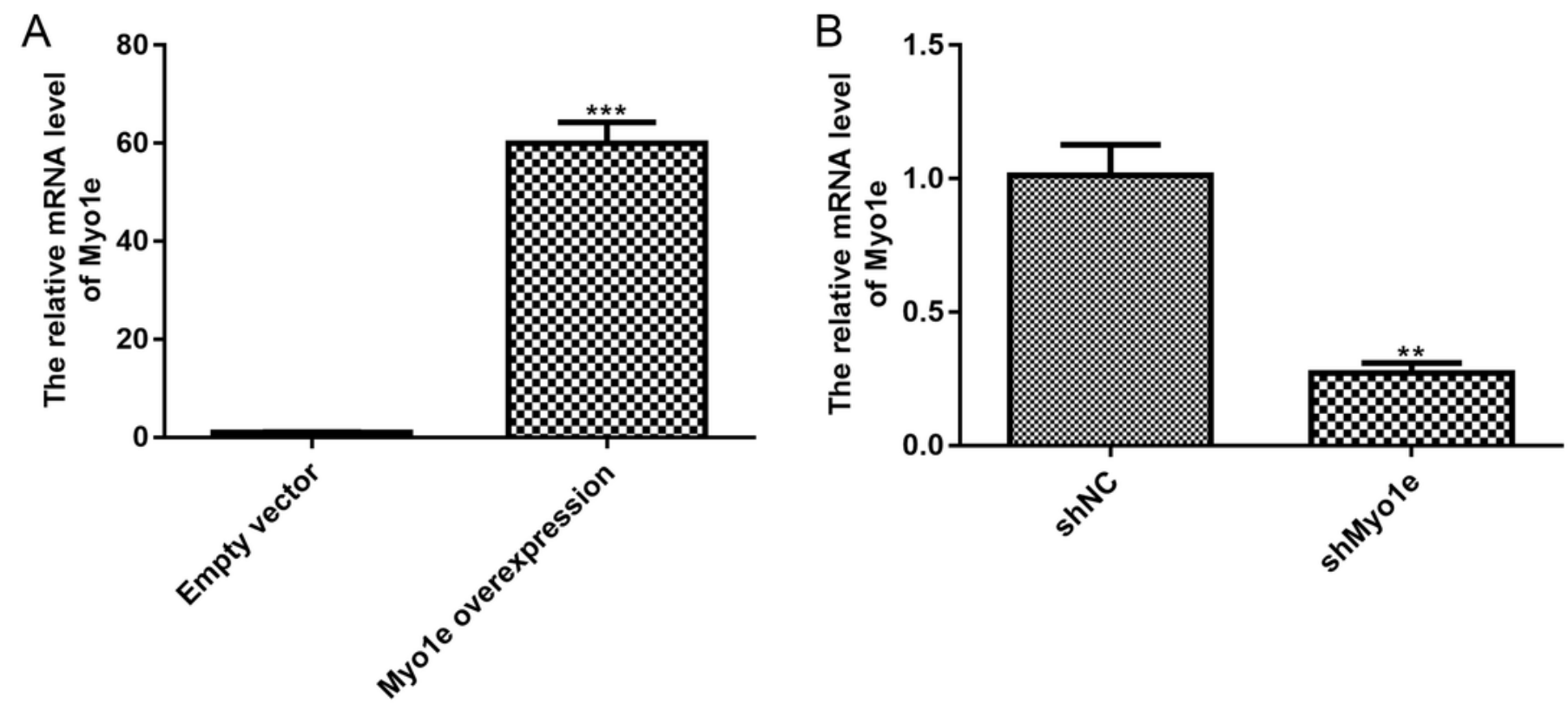


\section{Figure 3}

Overexpression of Myole enhances MPC5 glomerular podocyte endocytosis BSA.

(A, B) Flow cytometry assay results showing the endocytosis effects of MPC5 cells. (C) Immunofluorescence results showing the endocytosis effects of MPC5 cells. Scale bar, $50 \mu \mathrm{m}$. ***Myole overexpression vs. empty vector, $\mathrm{p}<0.001$; \#\#shMyole vs. shNC, $\mathrm{p}<0.01$.
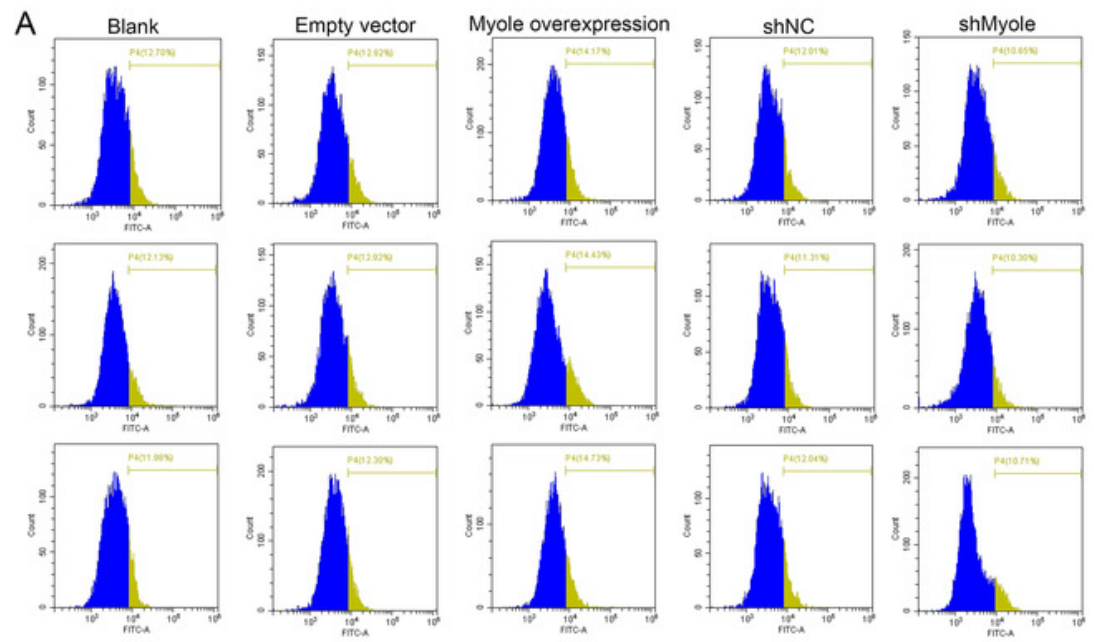

B

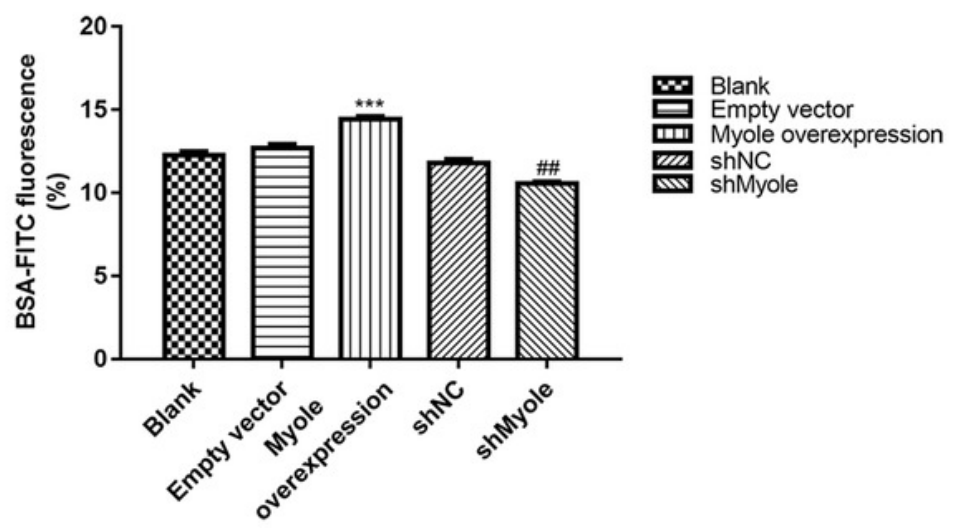

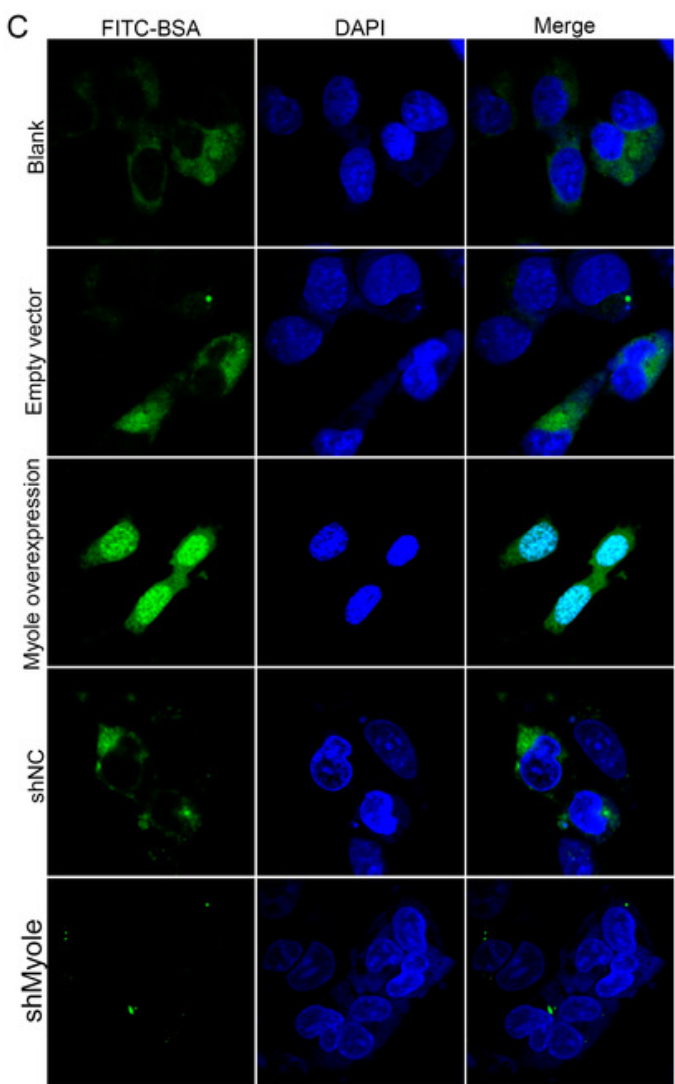


Figure 4

Morphology changes of MPC5 cells when overexpression or knockdown of Myole (100x, 200x). 

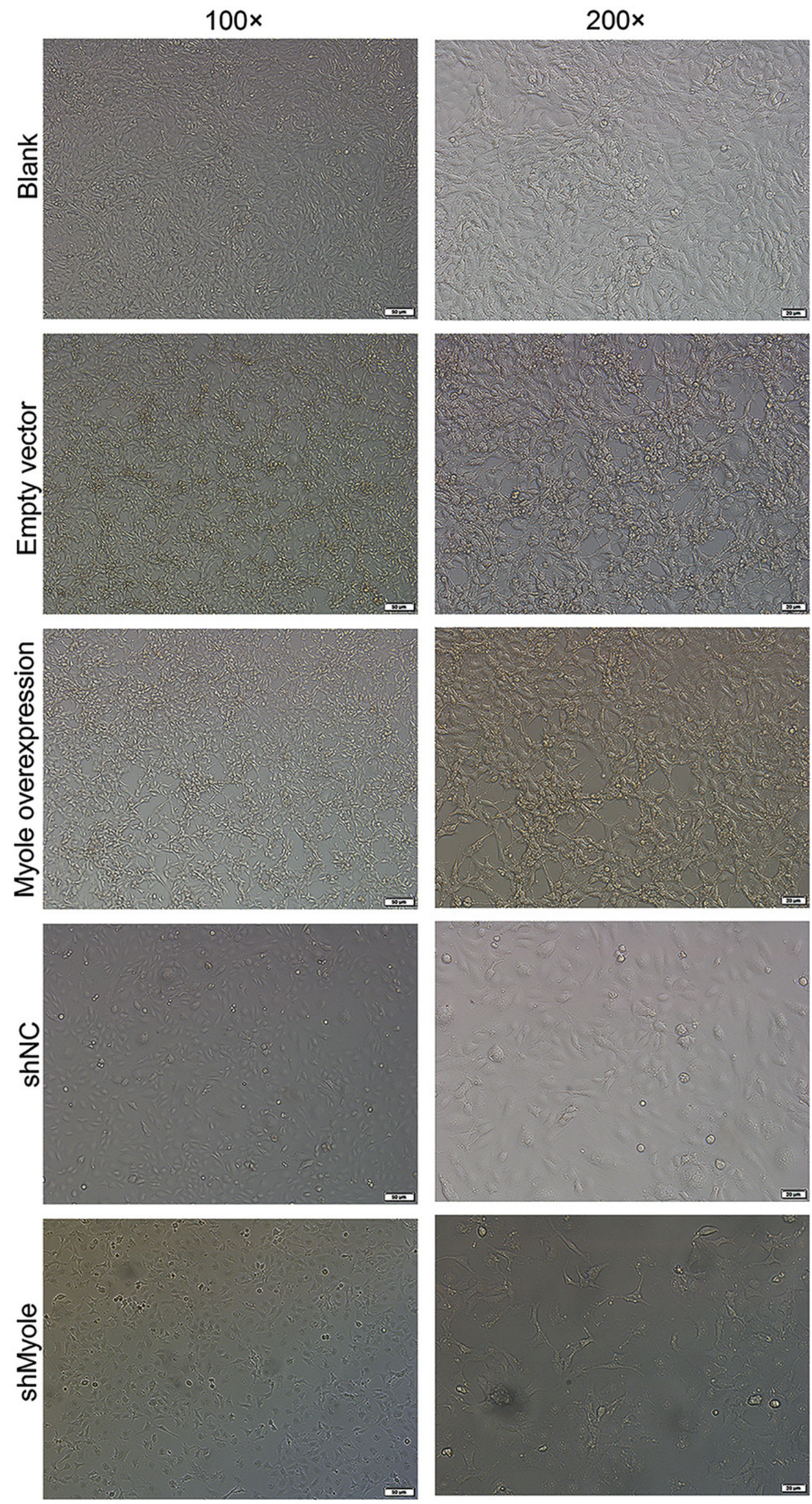

PeerJ reviewing PDF | (2019:09:41556:1:0:NEW 8 Jan 2020) 
Figure 5

Immunofluorescence detection of F-actin expression in MPC5 cells treated with Myole overexpression or knockdown. Scale bar, $50 \mu \mathrm{m}$. 


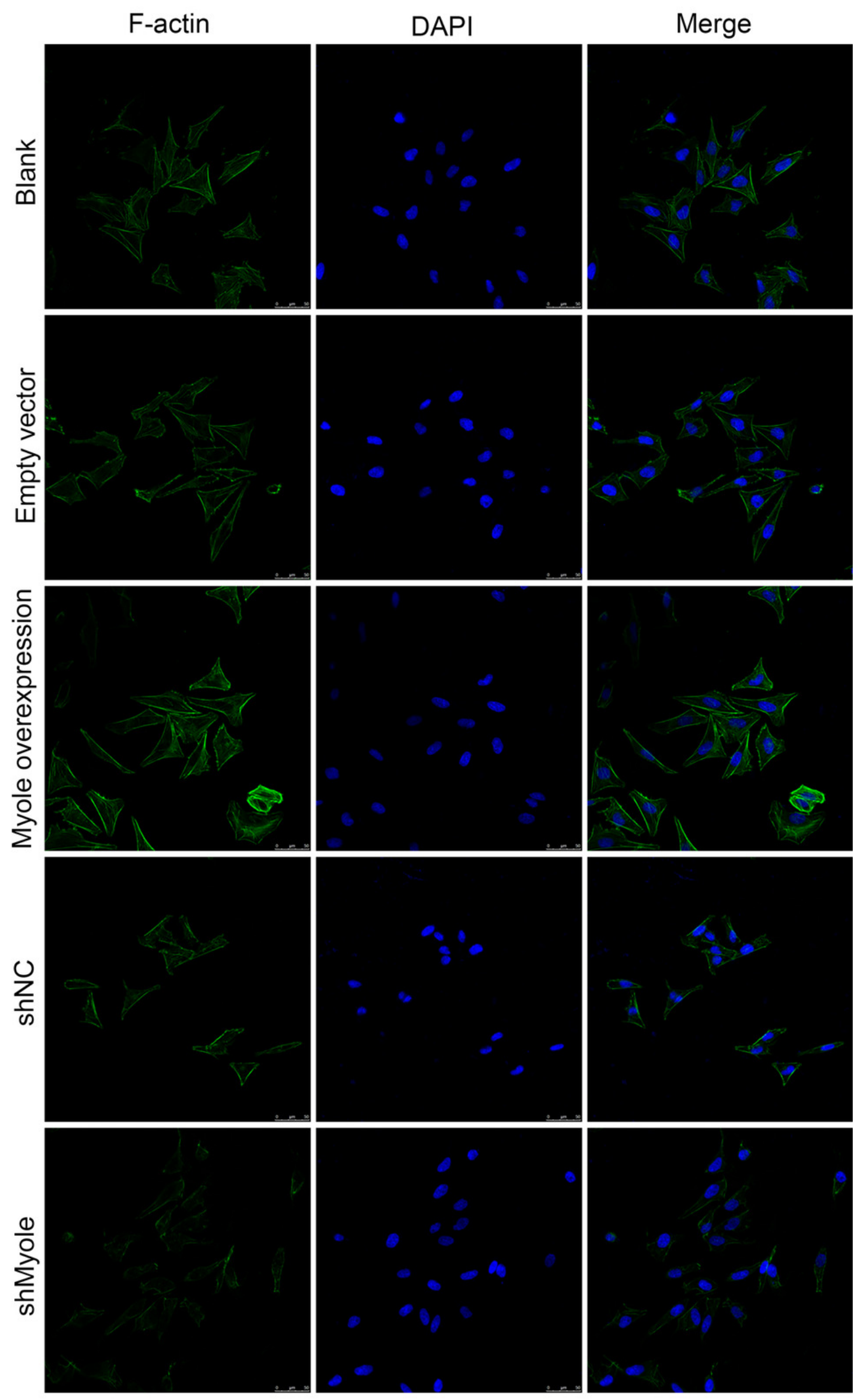

Peer) reviewing PDF | (2019:09:41556:1:0:NEW 8 Jan 2020) 


\section{Figure 6}

Western blot analyses showing the expression levels of nephrin and podocin in MPC5 cells treated with Myole overexpression/knockdown.

(A) Representative images of protein blots. (B) The expression levels of nephrin. (C) The expression levels of podocin. ${ }^{* *} p<0.01 ; * * * p<0.001$.

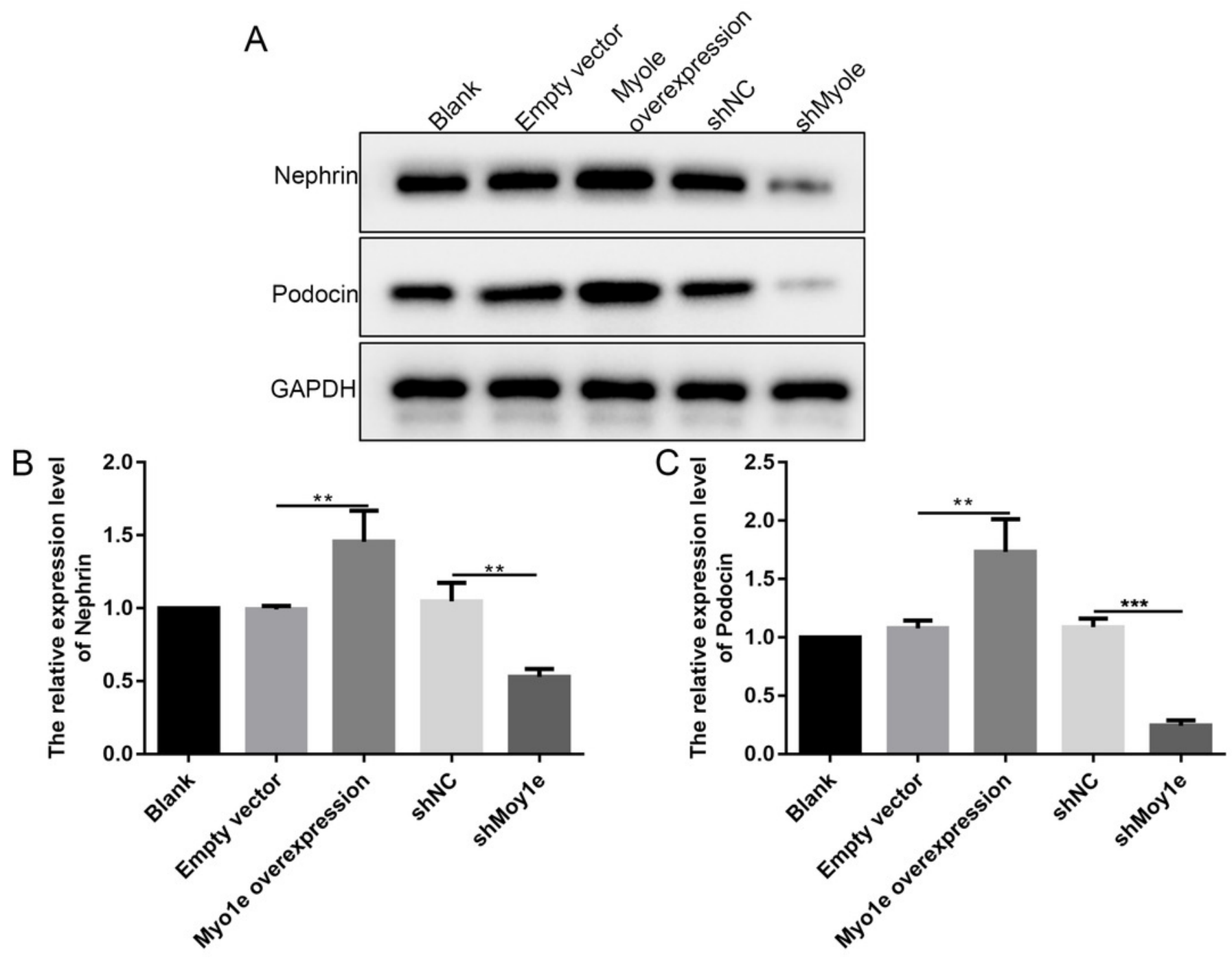


Figure 7

Myole may promote MPC5 cell apoptosis.

(A, B) Flow cytometry showing the apoptosis of MPC5 cells when treated with Myole overexpression/knockdown. * Myole overexpression vs. empty vector, $\mathrm{p}<0.05$; \#\#\# shMyole vs. shNC, $p<0.001$. 

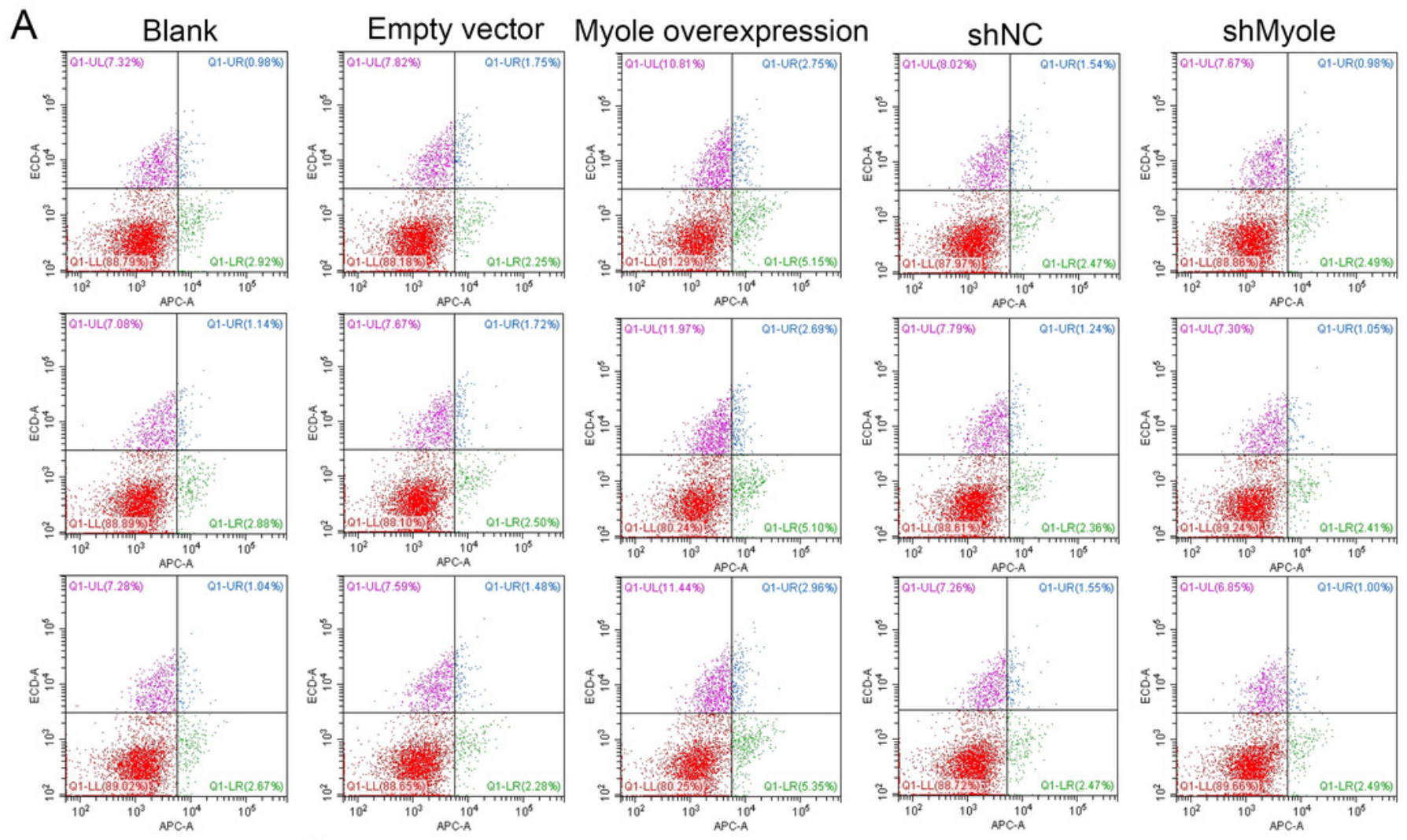

B

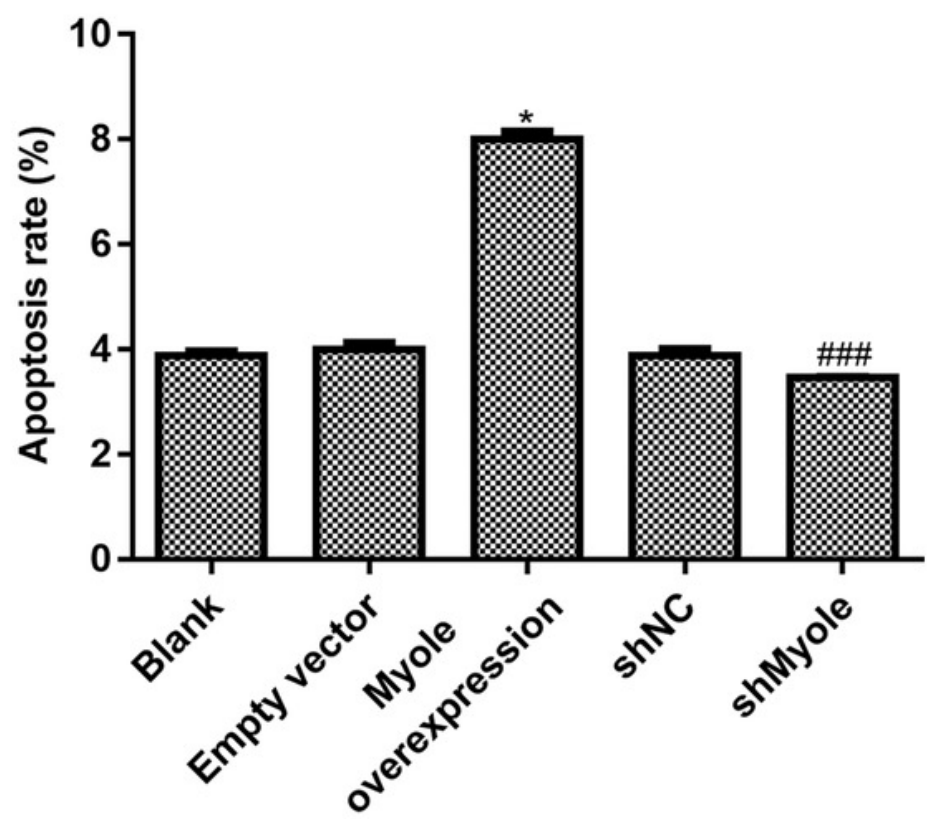


Figure 8

Myole might promote MPC5 endocytosis BSA mediated by Dynamin.

(A, B) Flow cytometry showing the endocytosis effects of MPC5 cells. (C, D) RT-qPCR showing the effect of Dynosore on both Myole and Dynamin expression. $* p<0.05 ; * * p<0.01 ; * * *$ $\mathrm{p}<0.001$.
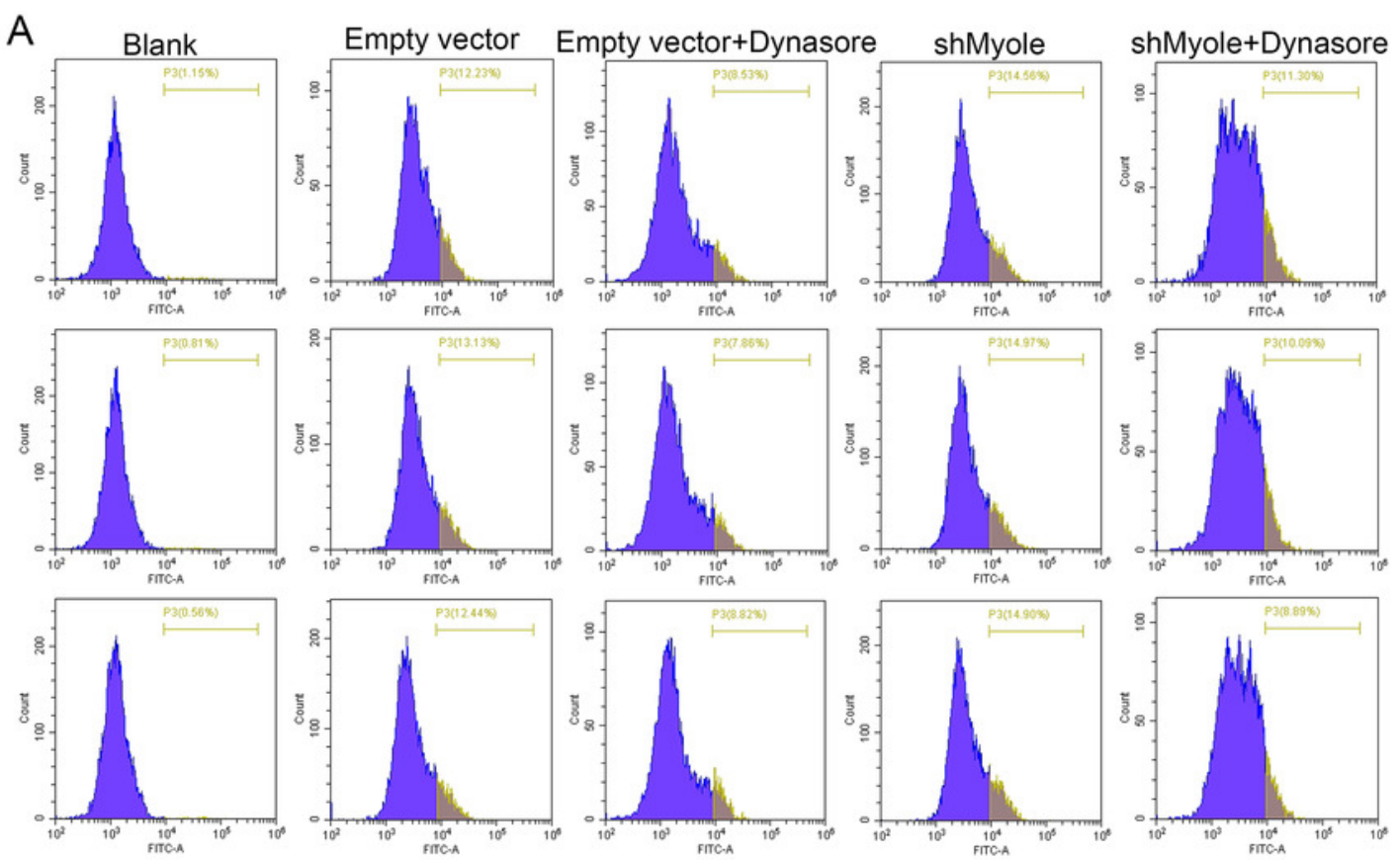

B

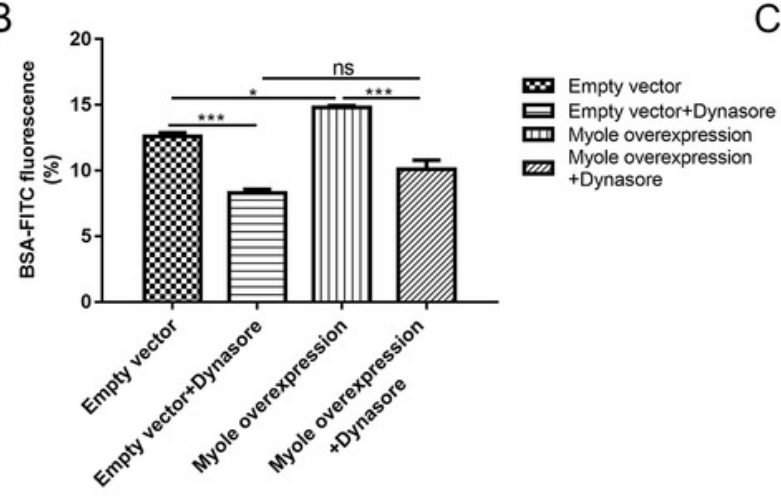

C

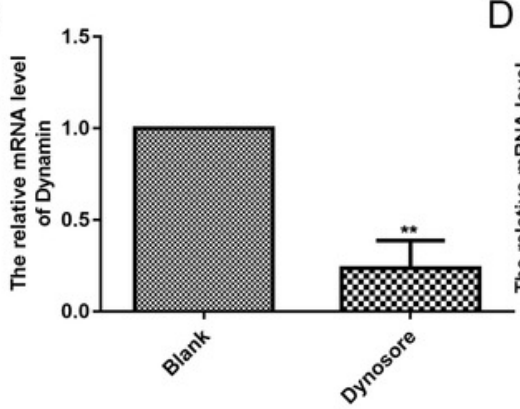

D

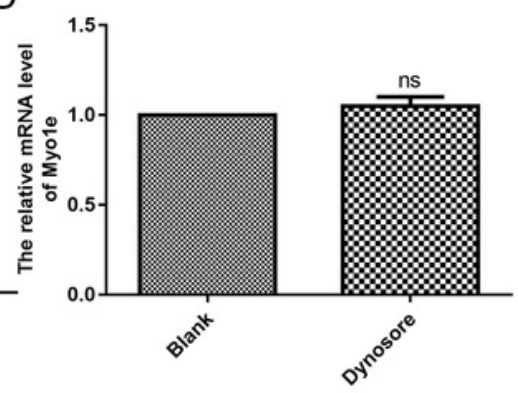


Figure 9

The effects of Dynamin overexpression or knockdown.

RT-qPCR results showed that Dynamin was successfully overexpressed (A) or silenced (B). $* * * p<0.0001$.
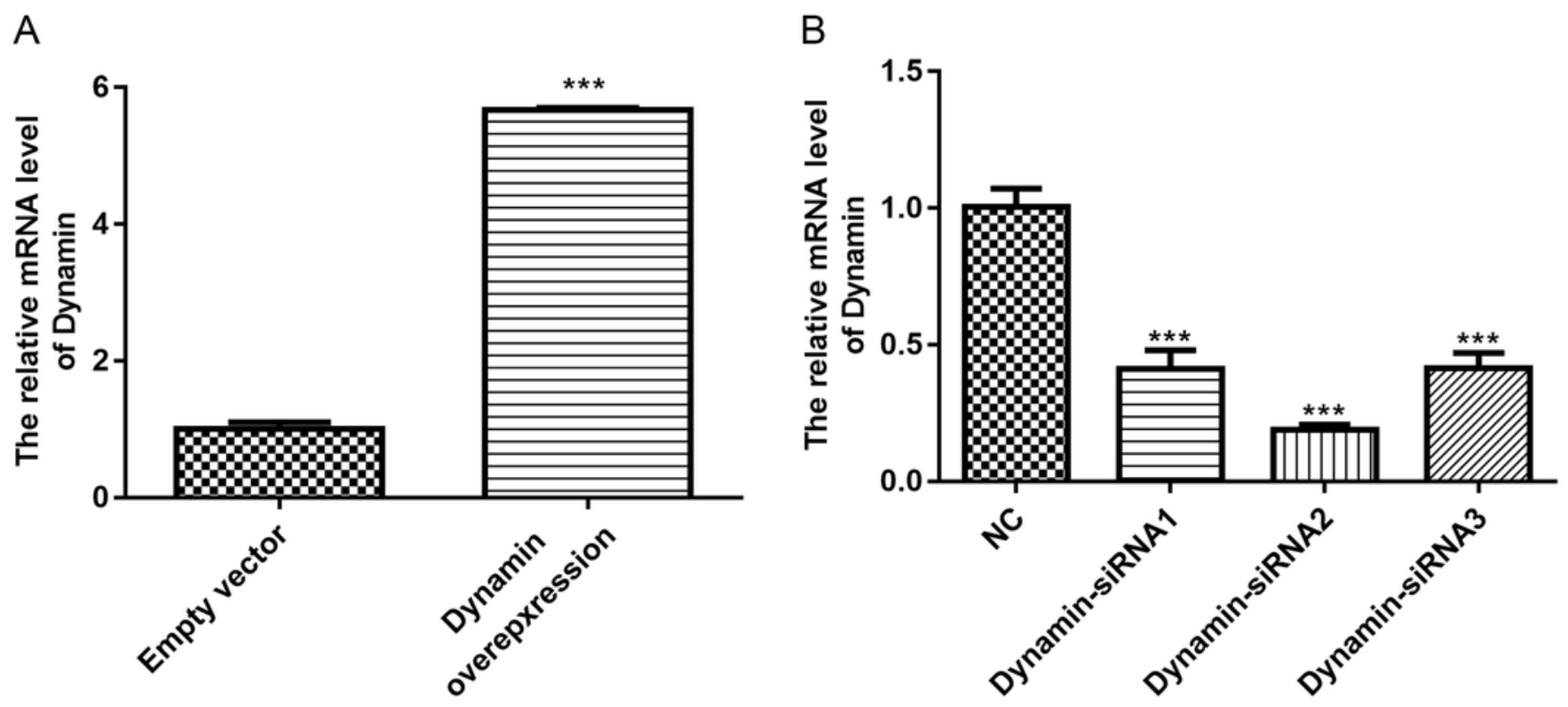
Figure 10

Immunofluorescence showing Myole might promote MPC5 endocytosis BSA mediated by Dynamin. Scale bar, $50 \mu \mathrm{m}$.
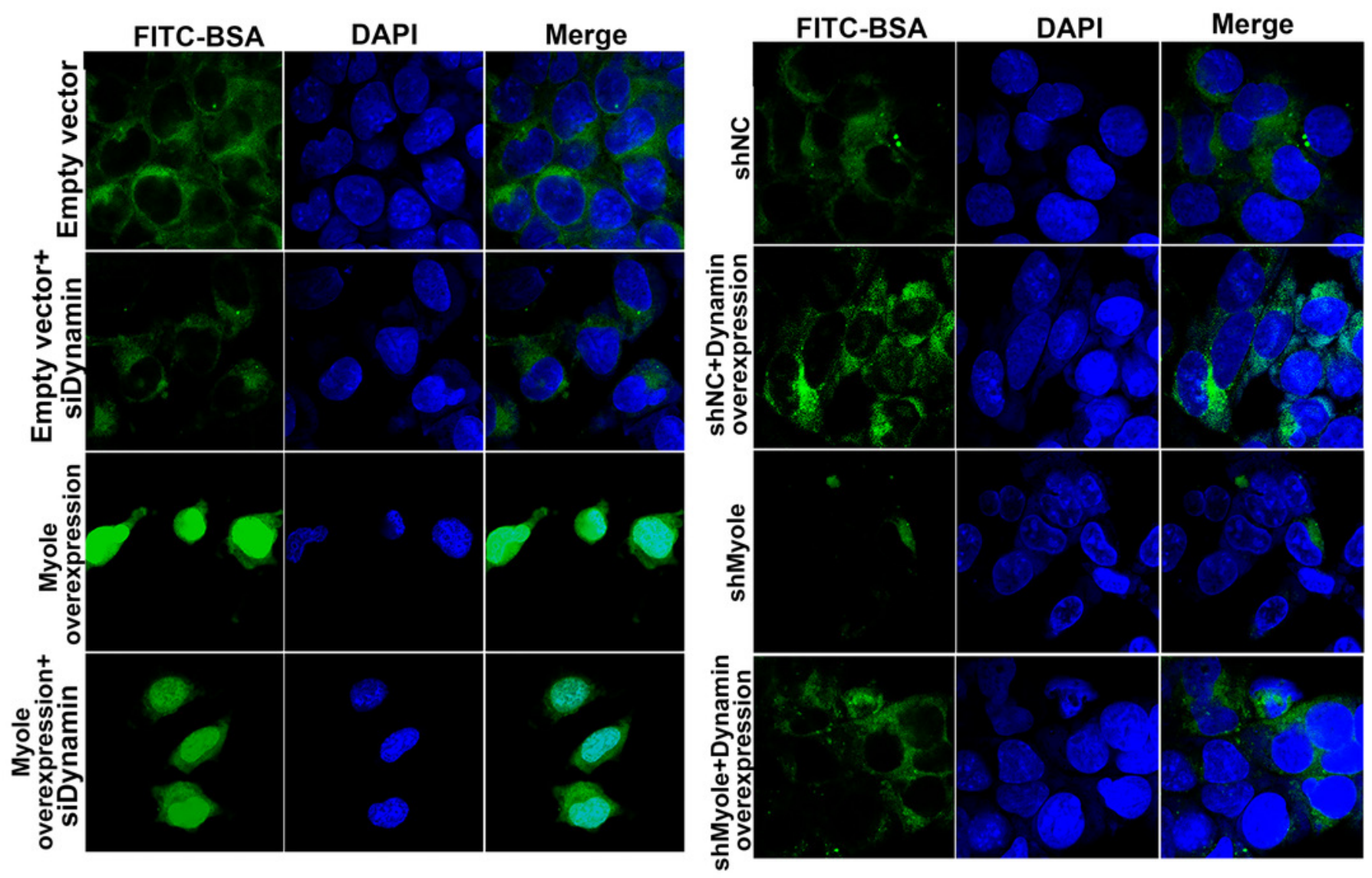